\title{
Arquitectura militar andalusí en Madrid capital: Nuevas perspectivas teóricas a raíz de las intervenciones arqueológicas de la plaza de Oriente y la plaza de la Armería (1999-2010)
}

\author{
Esther Andréu Mediero y Verónica Paños Cubillo \\ Arqueomedia, S.L. \\ verolo77@hotmail.com
}

No ha sido hasta los años 80 del siglo pasado, cuando el desarrollo de la arqueología urbana en la ciudad de Madrid, propició la aparición de numerosos hallazgos arqueológicos vinculados a época andalusí. Así, los testimonios arqueológicos junto con las crónicas árabes, son la evidencia de que existió un poblamiento islámico en la zona desde el siglo IX. La importancia y versatilidad de dichos hallazgos hace que en ningún caso puedan ser considerados "vestigios aislados", siendo en este punto donde versa la actual discusión arqueológica: ¿Qué tipo de asentamiento pudo existir en éste primigenio núcleo?

Tras años de investigación ${ }^{1}$, pretendemos ofrecer datos objetivos que apoyen la hipótesis de que Mayrit fue un núcleo militar desde su fundación en el siglo IX, hasta al menos mediados del siglo XI, momento en que quizás pudo alcanzar cierta consideración de madina, configurándose ya como realidad urbana bajo el mandato cristiano, una vez materializada la conquista cristiana en el año 1085. Existe total unanimidad por parte de los investigadores, a la hora de considerar la fundación de Madrid den-

1 E. ANDRÉU MEDIERO, “La plaza de Oriente. Antecedentes históricos”, Restauración \& Rehabilitación, 1 (1997), pp. 30-35; Ibídem, "Las excavaciones arqueológicas. Plaza de Oriente: Arqueología y evolución urbana”, E. ANDRÉU y S. PALACIOS (coord.), Plaza de Oriente. Arqueología y evolución urbana, Madrid, 1998; Ibídem, "La conservación de los restos en la arqueología urbana: la plaza de Oriente de Madrid", XXV Congreso Nacional de Arqueología, Valencia, 1999, pp. 320-324; Ibídem, "Las murallas de Madrid", Mérida, ciudad y Patrimonio. Revista de Arqueología, Arte y Urbanismo. 4, (2000), pp. 29-40; Ibídem, "Arqueología medieval de Madrid: Nuevas aportaciones acerca de su fortificación", Actas del II Congreso de Castellología Ibérica, Alcalá de la Selva (Teruel), 2001, pp. 419-432; Ibídem, "El Madrid medieval aparece", Restauración \& Rehabilitación, 52 (2001), pp. 36-43; Ibídem, "El Madrid medieval". XXVI Congreso Nacional de Arqueología (Zaragoza, 2001), Caesaraugusta, 78 (2007), pp. 687-698; Ibídem, "Excavaciones arqueológicas en la Plaza de la Armería de Madrid", Informes de las excavaciones arqueológicas, Dirección General de Bellas Artes y Bienes Culturales, Ministerio de Educación y Cultura, Madrid, 1999-2000; Ibídem,"Avance en el conocimiento del sector noroccidental de los recintos fortificados de la ciudad de Madrid", Mil anos de fortificaçoes na Peninsula Iberica e no Magreb (500-1500): Actas do simposio internacional sobre castelos, Lisboa, 2002, pp. 871-875. 
tro de la política de gobierno de Muhammad I, con respecto al reforzamiento de la Marca Media. Dicho emir, continúa el programa de fundación de núcleos militares tales como Talamanca del Jarama o Huesca, iniciado por su padre Abd-al-Rahman II, con el principal objetivo de consolidar el incipiente poder del Emirato de Córdoba ${ }^{2}$.

A colación de lo anteriormente expuesto, nos resulta muy significativo el hecho de que en las fuentes árabes se mencione a la población de Mayrit como hisn castral ${ }^{3}$ en los momentos más antiguos ${ }^{4}$, mientras que se refleja como medina en las crónicas más recientes ${ }^{5}$, correspondiendo estas últimas en el menor de los casos puesto que la mayor parte de las fuentes arábigas mencionan a Madrid de manera un tanto aislada y haciendo referencia casi siempre a actividades militares.

Las intervenciones arqueológicas a las que nos referimos ${ }^{6}$, evidencian la existencia de un primigenio núcleo de carácter militar o plaza fuerte surgido dentro de un complejo sistema de defensa y protección de la ciudad de Toledo, de las incursiones cristianas del norte, por un lado, y de las revueltas políticas internas de la propia ciudad de Toledo, por otro. Entendemos que la importancia militar del control de las zonas de paso de la sierra de Guadarrama, está en relación con la existencia de torres y ciudades/atalayas como puedan ser Calatalifa, Olmos o Talamanca ${ }^{7}$.

Los elementos arquitectónicos descubiertos en el transcurso de ambas excavaciones, son vestigios que han de vincularse, sin duda, a la arquitectura militar tanto emiral como califal. Estos restos arqueológicos se hallan profundamente relacionados entre sí conformando un todo: Una primigenia fortaleza andalusí, tipo hisn, de unas 8 hectáreas aproximadamente, origen de la ciudad de Madrid, tal y como citan las primeras fuentes. Por tanto, basándonos en los resultados ofrecidos a través de la arqueología en sendos yacimientos, no tenemos ningún elemento razonable que nos permita afirmar que el hisn de los comienzos fuera una realidad urbana, puesto que efectivamente, no se ha documentado in situ, ningún resto arquitectónico corres-

2 C. SEGURA GRAIÑO, "El origen islámico de Madrid y las relaciones con los reinos cristianos", Testimonios del Madrid medieval. El Madrid musulmán., Madrid, 2004:, pp. 19-42.

3 Para los especialistas Bazzana, Cressier y Guichard, un hisn era un asentamiento con función de refugio temporal al que se asociaban alquerías, poblaciones rurales asociadas. Vid. A. BAZZANA; P. CRESSIER y P. GUICHARD, Les chateaux ruraux d'al-Andalus. Histoire et archélogie des hûsun du sud est de l'Espagne, Madrid, 1988. En este sentido creemos necesario hacer una mención a los últimos hallazgos efectuados en Madrid con respecto a las excavaciones que acabamos de finalizar en la zona de Vallecas denominada Los Berrocales (Madrid) en relación a un posible hábitat rural de cronología islámica, que lógicamente se habría desarrollado como asentamiento bajo el influjo del Alcázar o núcleo militar.

4 Al-Razi, quien encuadra Madrid dentro del distrito de Madinat al-Faray, junto con otros núcleos "Y en su término (Guadalajara) se encuentran castillos y villas, de los que uno es el castillo de Madrid".

5 En el siglo XIII Mohamed al-Edrisi dice de Madrid que es una "pequeña villa bien poblada y castillo fuerte...". Dicho autor y geógrafo la describe como una ciudad pequeña, de no más de 4 hectáreas de extensión y bien poblada.

6 Las excavaciones de la Plaza de Oriente y calle de Bailén (dirigidas en 1992 por Sánchez Meseguer y Retuerce Velasco; entre 1994 y 1996 por Andréu y Retuerce; y en su última fase, entre 1996 y 1997, por Andréu y Malalana), y las excavaciones realizadas entre 1999-2000 y 2007-2010 en la Plaza de la Armería, para el Museo de Colecciones Reales de Patrimonio Nacional, dirigidas por Andréu.

7 M. MONTERO VALLEJO, "El entorno del alcázar de Madrid durante la Baja Edad Media", En la España Medieval, 7 (1985), pp. 1011-1026. También lo opina Cristina Segura, poniéndolo en relación con las revueltas de los muladíes y mozárabes de la Marca Media, C. SEGURA GRAIÑO, op. cit., 2004, p 28. 


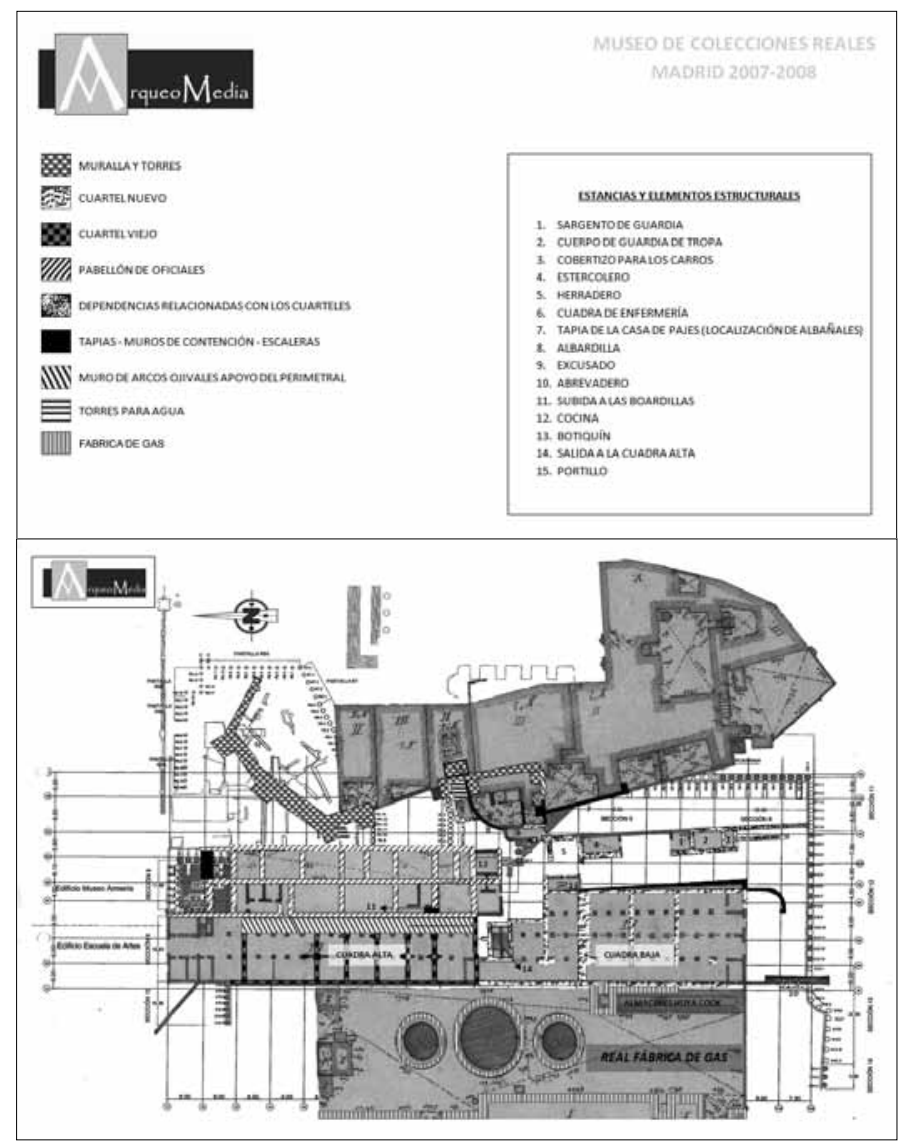

Fig. 1. Planimetría general de la excavación arqueológica efectuada para la construcción del Museo de las Colecciones Reales.

pondiente a estructuras civiles o de habitación, ni siquiera vinculadas a sistemas de irrigación, fechable en este primer momento fundacional de los siglos IX y X.

En todo caso, resulta posible que una medina del siglo XI, con su mezquita, zocos y baños, se originase hacia la zona de la actual calle Bailén en su cruce con la calle Mayor, pero desde luego, no en el área excavada por nuestro equipo, y mucho menos en el área extramuros fuera de este primer recinto, tal y como han reflejado otras intervenciones arqueológicas como la de la plaza de los $\operatorname{Carros}^{8}$ o la plaza del Rollo donde las cronologías islámicas son más tardías.

8 M. C. PRIEGO y M. RETUERCE, "Madrid: Barrio histórico. Informe de las excavaciones arqueológicas efectuadas en la plaza de los Carros (noviembre-diciembre, 1983)" Estudios de Prehistoria y Arqueología Madrileñas, Madrid, 1985, pp. 171-190.

9 R. MENASALVAS, y D. PÉREZ VICENTE, "Excavación arqueológica en el solar denominado Plaza del Rollo (Madrid)”, Arqueología, Paleontología y Etnografía, 3 (1992), pp. 227-251. 
Por tanto, aceptando el hecho de que la primitiva mezquita se erigiese bajo la posterior iglesia de Santa María, y teniendo en cuenta que en todo el espacio occidental por nosotros excavado no presenta restos urbanos, el espacio restante que ocuparía la posible medina, del siglo XI, sería bastante reducido. Por el contrario, los trabajos de excavación arqueológica en la plaza de la Armería y la plaza de Oriente (fig. 1), han permitido exhumar y documentar cuatro elementos arquitectónicos de carácter indiscutiblemente militar, que son el germen de lo que sería Madrid: muralla, albacar, atalaya defensiva y por último, una estructura destinada al alojamiento de las tropas o cuerpo de guardia.

Junto a estos elementos arquitectónicos de carácter militar, se documentaron en el transcurso de ambas excavaciones abundantes restos de basureros, silos y pozos, cortados en muchos casos por muros pertenecientes ya a viviendas bajomedievales, pero en ningún caso, estructuras civiles o habitacionales. Este hecho, unido a los materiales cerámicos que colmataban las estructuras negativas mencionadas, otorga una cronología islámica más antigua a los mismos, señalando por tanto, la existencia de tierras de labor en el interior de la primigenia fortaleza.

En este sentido, varios autores -Manuela Marín por ejemplo ${ }^{10}$ - señalan, al hablar del modo de vida de algunas guarniciones islámicas, que era habitual que cultivasen sus propias tierras "para obtener sustento en los alrededores del ribat".

En la misma línea de investigación de autores como Guichard ${ }^{11}$, nuestras hipótesis apuestan por la existencia de una organización territorial asentada en la existencia de un castillo, el alcázar islámico, núcleo militar y sede del poder por excelencia. Las fuentes árabes señalan con insistencia que Madrid tenía "castillo" en el siglo IX, dato por el que siempre se ha pensado que el alcázar se construyó en la colina de Palacio en el mismo momento de la fundación de Madrid por Muhammad I y de manera coetánea a la muralla. Esta idea, nos ofrece un primigenio núcleo en el que situaríamos al Alcázar -en la colina de Palacio- separado de los terrenos enmarcados en el recinto amurallado islámico ocupado en un principio por soldados y un posible e incipiente reducto de población civil.

Varios autores rechazan esta posibilidad, puesto que la mayor parte de los paralelos del territorio andalusí engloban la alcazaba en el interior del recinto amurallado. No obstante, este hecho llevó a que nos planteásemos diferentes hipótesis, pero finalmente, creemos en la posibilidad de que el Alcázar pudiera haberse edificado de manera coetánea al albacar, esto es, hacia el siglo X y no en el siglo IX. Ello supondría que no se habría concebido nunca de manera separada a la medina y reforzaría la idea de un núcleo militar primitivo amurallado en el siglo IX, donde por qué no, se hubiera construido un pequeño castillo o donjon, sede del poder establecido. "Castillo" que podría ser el que se menciona en las fuentes árabes como levantado en el siglo IX.

10 M. MARÍN, "El ribât en Al-Andalus y el Norte de Africa", La Rábita en el Islam: estudios interdisciplinares: congressos internacionals de Sant Carles de la Ràpita (1989, 1997), Alicante, 2004, pp. 111-116; Ibídem, "La práctica del ribât en al-Andalus (ss. III-V/ IX-XI)", R. AZUAR (coord.), El ribat califal. Excavaciones y estudios (1984-1992), Madrid, 2004, pp. 191-201.

11 P. GUICHARD, Al-Andalus. Estructura antropológica de una sociedad islámica en Occidente, Granada, 1994. 
Aunque, siendo cautos con la interpretación de las fuentes históricas, nos inclinamos a pensar que el término sólo aluda a un enclave fortificado.

Junto a este primitivo alcázar muy posiblemente existió una mezquita que prestase el servicio religioso a las autoridades militares, soldados y familiares. Según nuestras últimas investigaciones tendemos a creer en la posibilidad de que la iglesia de San Miguel de la Sagra hubiera sido la mezquita principal del Alcázar de Madrid con anterioridad a convertirse en la parroquia de la colación de San Miguel. En éste sentido sería interesante considerar que lo que existió en Madrid puede relacionarse con lo que el autor Mikel de Epalza denomina "mezquitas de los campamentos militares de implantación" 12 .

\section{MURALLA}

Los orígenes del recinto amurallado islámico de Madrid se remontan al momento de la fundación de este enclave en el siglo IX, bajo el mandato del emir Muhammad I, siendo por tanto un elemento arquitectónico con características propias del periodo emiral, si bien, tiene añadidos fruto de reformas que se produjeron posteriormente, durante el periodo califal.

El emplazamiento de la muralla islámica del primer recinto en el solar de la cuesta de la Vega hace tiempo que quedó confirmado por los hallazgos "casuales" realizados por J. Oliver Asín, L. Torres Balbás y F. Chueca Goitia en el año 1953. Desde entonces, las intervenciones arqueológicas han ido exhumando diversos lienzos de muralla en la misma cuesta de la Vega, calle Mayor, pretil de los Consejos y plaza de la Armería, otorgándonos el esquema de su recorrido, confirmado en casi todos los tramos a excepción del cierre septentrional de la misma. Tradicionalmente se había planteado el cierre norte del recinto islámico atravesando la plaza de Oriente, y ciertamente sobre el papel resulta lo más coherente, pero durante las excavaciones arqueológicas efectuadas, no aparecieron restos de ningún muro o cimentación que pudiera pensarse que perteneciese a la cerca: Las excavaciones constataron que estábamos ante una zona extramuros dedicada a la agricultura y actividades artesanales hasta bien entrada la Baja Edad Media. Además, hemos de señalar que este espacio se encontraba surcado por numerosas cárcavas y barrancos, siendo un terreno poco apto para situar una cerca defensiva por lo que tras la excavación planteamos que el cierre septentrional habría de discurrir por los Altos de Rebeque. De éste modo, partiendo de la cuesta de la Vega ${ }^{13}$, el trazado de la muralla continuaría hasta cruzar la calle Mayor, donde estaría la puerta de Santa María, y desde aquí ascendería por los Altos de Rebeque, actual calle de Factor, para cruzar la calle de Bailén, y bordeando una cava documentada en la excavación de la plaza de la Armería (cava de la Sagra),

\footnotetext{
12 M. DE EPALZA, "Mutaciones urbanísticas debidas a la transformación de mezquitas en iglesias", $I V$ Simposio Internacional de Mudejarismo, Teruel, 1993, pp. 501-513.

13 L. CABALLERO et alii, "Las murallas de Madrid. Excavaciones y estudios arqueológicos (1972 a 1982)", Estudios de Prehistoria y Arqueología Madrileñas, Madrid, 1983; L. CABALLERO ZOREDA, "Excavaciones arqueológicas en el casco histórico de Madrid", Villa de Madrid, 80, II (1985), pp. 55-58.
} 


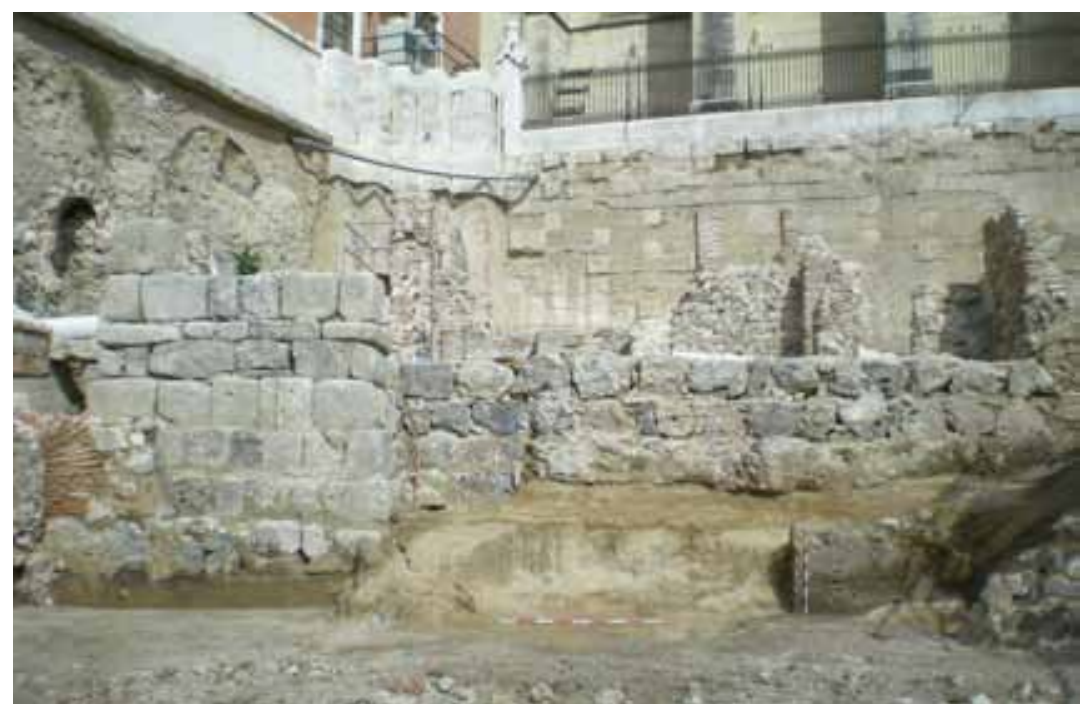

Fig. 2. Tramo perteneciente a la muralla islámica y torre anexa (siglo IX) exhumadas en la explanada situada entre la Plaza de Armas y la Catedral de la Almudena.

llegaría al pretil del Campo del Moro. Así, por tanto, la Puerta de la Xagra -única de las tres principales puertas del recinto cuya ubicación exacta se desconoce- se encontraría en algún punto que permitiese la comunicación con los campos de cultivo de la zona norte (actual plaza de Oriente) y oeste (Campo del Moro). Si bien, no podemos afirmar con total seguridad que esta ubicación de la puerta sea la certera, sabemos al menos por la documentación de archivo que seguía en pie a principios del siglo XVI dado que contamos con un documento fechado entre los años 1511- 1531 que dice "Se adobó la puerta de la Sagra" 14 .

La intervención arqueológica efectuada en la explanada situada entre la plaza de la Armería y la catedral de La Almudena, ha permitido documentar dos lienzos de muralla islámica que en total suman más de $70 \mathrm{~m}$ lineales (fig. 2). Sin embargo, en la zona más "oriental" del yacimiento, no se conserva resto alguno de cimentación de la muralla islámica dado que la construcción de la Real Armería durante el reinado de Felipe II provocó la destrucción del lienzo en ésta parte, así como el robo de los materiales que conformaban la cimentación. Pero, milagrosamente, pudimos documentar la fosa de cimentación (el negativo) rellenado con arena de miga, y la gruesa capa de argamasa de cal que servía de revoco al interior del paseo de ronda, que también se mantuvo. En otras zonas apenas se han conservado restos de la zarpa de aproximadamente 1,50 m de altura, como en la denominada Zona 2 del yacimiento arqueológico, donde el tramo de muralla islámico descubierto bajo el patio de la Casa Chica de

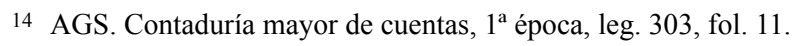


Pajes presenta una anchura de 3'10 m, levantando una altura máxima de 1'90 m, y descansando el paño en un único escalón a modo de zarpa de 0 '70 $\mathrm{m}$ de altura.

La fábrica de la muralla se compone de grandes sillares de piedra caliza y sílex trabados con argamasa amarillenta clara, tratándose de sillares reutilizados de época romana. La cerca conserva en la cara interna el típico paramento medieval-islámico, formado por mampuesto de mediano tamaño, aunque en ciertas zonas de la cara exterior se encuentra forrada de mampostería del siglo XIX, al igual que ocurre en parte de la sección inferior del lienzo de la muralla islámica de la cuesta de la Vega, donde se localizan ladrillos de cronología moderna.

Con respecto a las torres de flanqueo de la muralla, las documentadas en el tramo de muralla de la Armería son de planta cuadrangular, siguiendo la típica técnica de fortificación omeya. Durante la primera fase de intervención (1999-2000), se documentaron cuatro torres cuadrangulares. La torre $\mathrm{n}^{\circ} 1$, de planta cuadrada, presentaba unas medidas de 2'13 por 2'36 m y una altura de 3’26 m. La fábrica de esta torre, difiere de la fábrica de otras torres documentadas en esta excavación y también de las documentadas en la cuesta de la Vega ya que, en este caso, los sillares son de granito. Las torres $\mathrm{n}^{\circ} 6$ y 3 , miden $5 \mathrm{~m}$ por $2^{\prime} 50 \mathrm{~m}$, ambas se hallaron en muy buen estado de conservación, sin embargo, el resto de las torres documentadas en la primera campaña, esto es, las torres $\mathrm{n}^{\circ} 2$ y 4 estaban camufladas bajo construcciones posteriores al siglo XVI, con lo que no ha resultado posible establecer sus medidas.

En relación al tema de las puertas o accesos de la muralla, la excavación de la plaza de la Armería permitió constatar la existencia de un portillo. La ubicación en éste punto de dicho portillo, ya era conocida gracias al grabado del pintor flamenco Anton Van Den Wyngaerde (Vistas de Madrid de 1562). En este caso, podemos pensar que se trata del acceso mencionado por Mesonero Romanos en 1861, y del mismo modo, también podría referirse al portillo de la Cuesta de la Vega citado por Madóz. Con respecto a la tipología del mismo, el portillo presenta unas jambas realizadas con sillares de sílex o pedernal y algún sillar de granito de grandes dimensiones.

\section{EL $A L B A C A R$}

Entendido como recinto exterior, que precede al recinto principal fortificado o alcázar, es un elemento de la arquitectura militar islámica al que se le atribuyen varias funciones: alojar a las caballerizas y en ocasiones al cuerpo de guardia, y en caso de peligro, servir para refugio de la población aledaña incluyendo su ganado; o simplemente, lugar donde las gentes de la fortaleza guardaban sus reses hasta que fueran a consumirlas. De hecho, etimológicamente albacar deriva del árabe al baqqara (ganado vacuno).

La cimentación hallada en la excavación de plaza de Oriente identificada como la base de un albacar ${ }^{15}$ (fig. 3), posee una función íntimamente relacionada con la defensa del territorio y con un cambio político-reformador inserto en el mandato del

15 Interpretación planteada por Esther Andréu, y compartida por Antonio Malalana Ureña (Universidad San Pablo-CEU) y por el Dr. Luis de Mora-Figueroa (Universidad de Cádiz). 


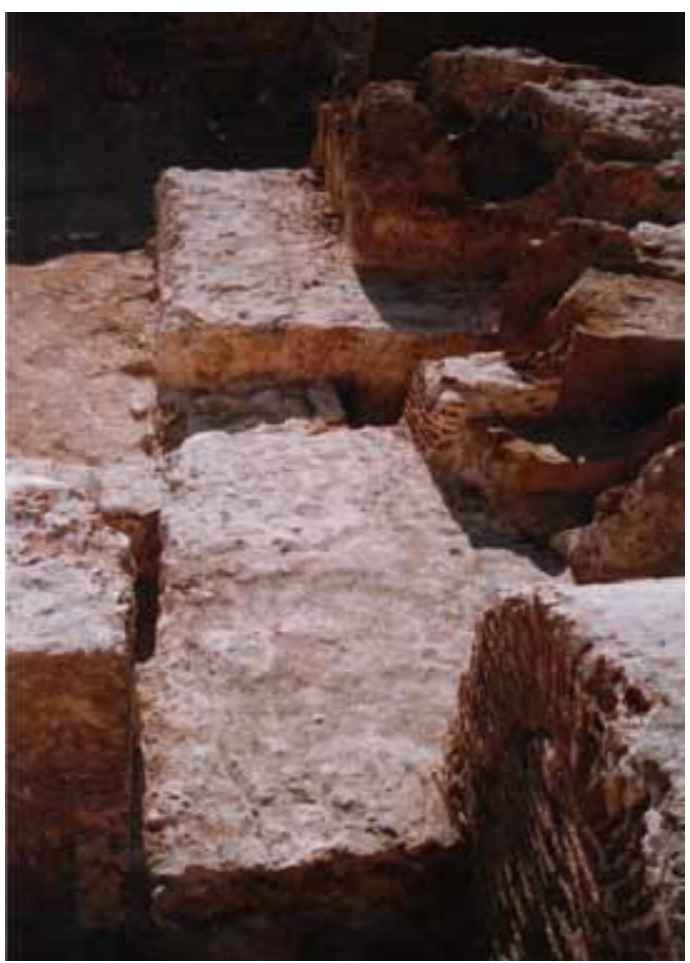

Fig. 3. Detalle del cimiento altomedieval (mediados del siglo X), hallado en el transcurso de las excavaciones de Plaza de Oriente e identificado como cimiento perteneciente a un posible albacar islámico.

califa Abd-al-Rahman III (929-961). Según las crónicas, Abd-al-Rahman III dirigió personalmente un programa de refuerzo de las fortalezas, atalayas y torres de la Marca Media y su frontera con la Marca Superior. Parece ser que las reformas promovidas por el gobierno de Abd-al-Rahman III, y la cada vez mayor presión de los reinos cristianos, materializada en el año 932 con el asedio de Ramiro II a la fortaleza de Madrid, fueron los hechos históricos que conllevaron las reformas, más que urbanísticas defensivas, en el entorno que nos ocupa. A la cimentación exhumada se le asigna una fecha de mediados del siglo $\mathrm{X}^{16}$. Durante la excavación arqueológica, vieron la luz $11^{\prime} 90 \mathrm{~m}$. de lo que fue esta estructura, sirviendo de cimentación del muro de fachada norte de la Casa del Tesoro del siglo XVI.

Desde el punto de vista tipológico, presentaba una orientación este-oeste, de $2 \mathrm{~m}$. de ancho y 2'20 m de potencia, además de anclajes en el terreno natural y restos de

\footnotetext{
${ }^{16}$ La datación de ambas estructuras fue posible gracias a los análisis de termoluminiscencia realizados por los profesionales Tomás Calderón García, Pedro Benéitez Moreno y Asunción Millán Changoyen , miembros del GI "Grupo Español de Luminiscencia aplicada" perteneciente al departamento de Geología y Geoquímica de la Universidad Autónoma de Madrid.
} 
madera en la fosa de fundación. El cimiento fue edificado a base de mampostería y en su parte superior se documentaron restos de paja, lo cual unido al hallazgo de los restos de madera indica que sostuvo algún muro de tapial del que, lógicamente, no ha quedado más huella. Desde varias perspectivas historiográficas se ha pretendido atribuir una función ganadera, exclusivamente, a los albacares, negando su función defensiva por lo endeble de su construcción; pero existen claros ejemplos de utilización de tapial y ladrillo en fortalezas y murallas ${ }^{17}$.

Éste sería el caso de la alcazaba de Toledo, construida en tapial a finales del siglo VIII aunque se reformó con posterioridad en época de Abd-al-Rahman II o el de las murallas de Badajoz, las cuales, según al-Himyari, se edificaron en el siglo IX utilizando este material ${ }^{18}$. Tanto la fábrica como las características tipológicas dan como certera la cronología califal para la cimentación del albacar.

De este modo, cobra sentido la hipótesis de que dicha estructura se construyese en momentos posteriores a la edificación de la muralla, de cronología emiral, con la finalidad de reforzar las defensas en momentos de asedio. A pesar de ser esta última su función principal, el albacar habría servido también para guardar el ganado que servía para abastecer a las tropas.

Resulta comprensible que con la construcción del alcázar de la dinastía Trastámara en el siglo XIV, se produjese la desaparición del albacar.

Entendemos que en este momento histórico, resulta innecesario un elemento de carácter defensivo, ya que hasta las propias murallas pierden su carácter originario para adquirir funciones fiscales. Del mismo modo ocurre con el alcázar, el cual evoluciona hacia modelos cortesanos. El espacio ocupado por el antiguo albacar andalusí se convertirá posteriormente en plaza de armas.

El descubrimiento del albacar nos ha permitido crear un nuevo esbozo de este primigenio núcleo hacia el siglo X: Tendríamos por un lado el alcázar islámico, situado en la colina homónima, y tanto de su costado oriental como del occidental, se proyectaría el albacar, levantado en tapial. De este modo, del flanco oriental, el muro partiría en línea recta bordeando el escarpado barranco que mira al Manzanares, salvando el foso del alcázar y el recinto amurallado. Atravesaría lo que hoy conocemos como "Campo del Rey" hasta entroncar con la esquina NO del recinto militar amurallado y posterior medina. En ese punto, el muro del albacar entroncaría con la muralla de cronología emiral a la altura de donde creemos pudo haber estado ubicada la Puerta de la Sagra. Por otra parte, en el flanco occidental, el muro que levantaba en tapial partiendo del alcázar llegaría hasta el arroyo de Tenerías, a partir de donde bajaría de forma paralela al muro oriental, salvando también ambos fosos, atravesando el "Campo del Rey", y entroncando con la muralla en algún punto del NE de la misma.

Paralelos al albacar de la fortaleza madrileña podemos encontrarlos en las poblaciones de Molina de Aragón, Atienza o Hita, Torre Arboles, Cantarrayán o Santi Petri. En el norte de África son reseñables los albacares de Ceuta, Arcila, Alcazarseguer o Tánger, predominando en todos ellos la función agropecuaria frente a la defensiva.

17 R. AZUAR, "Las técnicas constructivas en al-Andalus: el origen de la sillería y del hormigón de tapial", $V$ Semana de Estudios Medievales, Nájera del 1 al 5 de agosto, Logroño, 1995, pp.125-142.

18 Ibidem, p. 133. 
Queremos destacar también el albacar del castillo de Carabanchel/Monreal, estudiado por Santiago Palacios Ontalva ${ }^{19}$, siendo un recinto avanzado que además de acoger ganado y caballerizas englobaría un antecastellum que en palabras de Palacios, "se trataría de un espacio individualizado que por medio de un foso interior y otra cortina de muralla constituía un recurso defensivo de larga tradición" ${ }^{20}$.

\section{ATALAYA}

Con respecto a la atalaya o torre de vigilancia aparecida en la intervención de la plaza de Oriente ${ }^{21}$ (fig. 4) tendría la función de cubrir las necesidades de defensa del contingente militar, encargándose de la vigilancia desde un punto estratégico. Defendía además el espacio denominado sagra (actual plaza de Oriente), que al quedar fuera del recinto amurallado quedaba desprotegido. Es de suponer que debía ir acompañada de otras torres vigías en las inmediaciones, como sucede en el caso de la red de atalayas que controlaban los pasos y puertos de la Sierra de Guadarrama, aunque por el momento no han sido descubiertas.

Los restos de la torre vigía documentados, presentan una planta rectangular, con unas medidas de $3,65 \times 3,40 \mathrm{~m}$. Los vestigios conservados actualmente bajo la plaza de Oriente se componen de una fábrica de mampostería de sílex y caliza, con sillares en los esquinales que reforzaban la construcción. Resulta obvio, que esta atalaya controlaría el posible camino del Barranco del Arenal y las diferentes huertas de la zona en un punto intermedio entre el alcázar ${ }^{22}$ y las fuentes de los Caños del Peral ${ }^{23}$.

En cuanto a la interpretación que realizamos de esta atalaya, hemos de decir que en un principio, nos planteamos la posibilidad de haber hallado la denominada torre Gaona, ya que su ubicación en este punto había sido propuesta por varios autores ${ }^{24}$. Dicha propuesta fue descartada inmediatamente puesto que la propia excavación arqueológica, evidenció que, tras haber sido derruida, los estratos que se encontraban sobre los restos de la atalaya correspondían a época bajomedieval, y eso evidenciaría que en época moderna esta torre se mantuvo enterrada. Hemos de recordar que precisamente la torre Gaona, pervivió durante esos años posteriores.

19 S. PALACIOS ONTALVA, Fortalezas santiaguistas: la orden en la ribera del Tajo (siglos XII-XVI), Cuenca, 2006.

20 Ibidem, p. 109.

21 E. ANDRÉU y S. PALACIOS, op. cit., 1998.

22 E. ANDRÉU y M. RETUERCE, Informe de la excavación arqueológica de la plaza de Oriente y calle Bailén: primera fase. Plaza de Oriente. Memoria presentada a la comunidad de Madrid en junio de 1995, p. 41.

23 Situada en la actual Plaza de Isabel II y construida en el siglo XVII, parte fue excavada y documentada con motivo de las intervenciones arqueológicas en relación con las obras de metro llevadas a cabo en la estación de Opera dirigidas por Gregorio I. Yáñez Santiago en 1990. En el año 2009, con motivo de nuevas obras se recuperó en su totalidad bajo la intervención arqueológica dirigida por Eduardo Penedo Cobo. Actualmente se pueden ver los restos arqueológicos de la fuente en museo construido bajo la estación de metro de Opera de Madrid.

24 L. CABALLERO et alii, op. cit., 1983, pp. 25-26; M. RETUERCE,. «El agua en el Madrid andalusí», Historia del abastecimiento y usos del agua en la villa de Madrid, Madrid, 2001, pp. 35-54. 


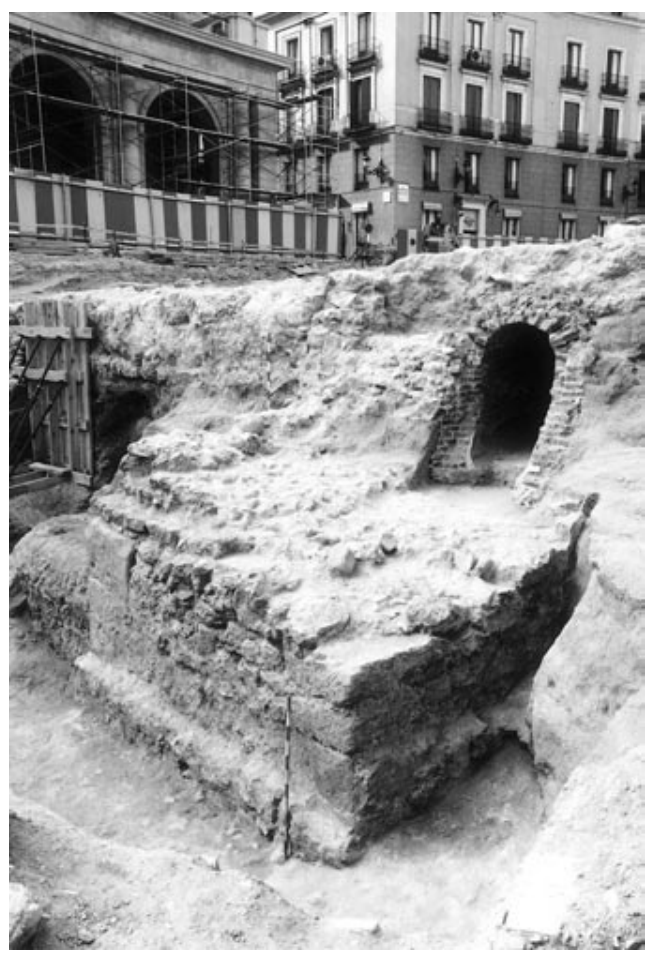

Fig. 4. Atalaya islámica (siglo XI) descubierta en la intervención arqueológica de Plaza de Oriente.

Tras la excavación y documentación arqueológica de la estructura se efectuó un análisis de termoluminiscencia tomando diversas muestras de ladrillos y materiales cerámicos con el fin de determinar el periodo de construcción de la atalaya. Los resultados obtenidos mostraron claramente que el último proceso de calentamiento enérgico de estos materiales tuvo lugar aproximadamente en la segunda mitad del siglo XI, siendo por tanto fechada la estructura en este momento.

\section{EL ALOJAMIENTO PARA EL CUERPO DE GUARDIA}

La estructura que identificamos como destinada al alojamiento para el cuerpo de guardia (fig. 5) apareció en la denominada zona 2 del yacimiento arqueológico de la Armería durante la última campaña efectuada entre los años 2007-2010. Se trata de los restos de un pequeño edificio que se divide en tres pequeños habitáculos dispuestos linealmente y que están adosados todos ellos a la muralla, encontrándose comunicados entre sí. Las estancias muy posiblemente siervieron para resguardar a los soldados y guardias en zonas estratégicas, sobre todo en puntos situados en las inmediaciones de las torres. 


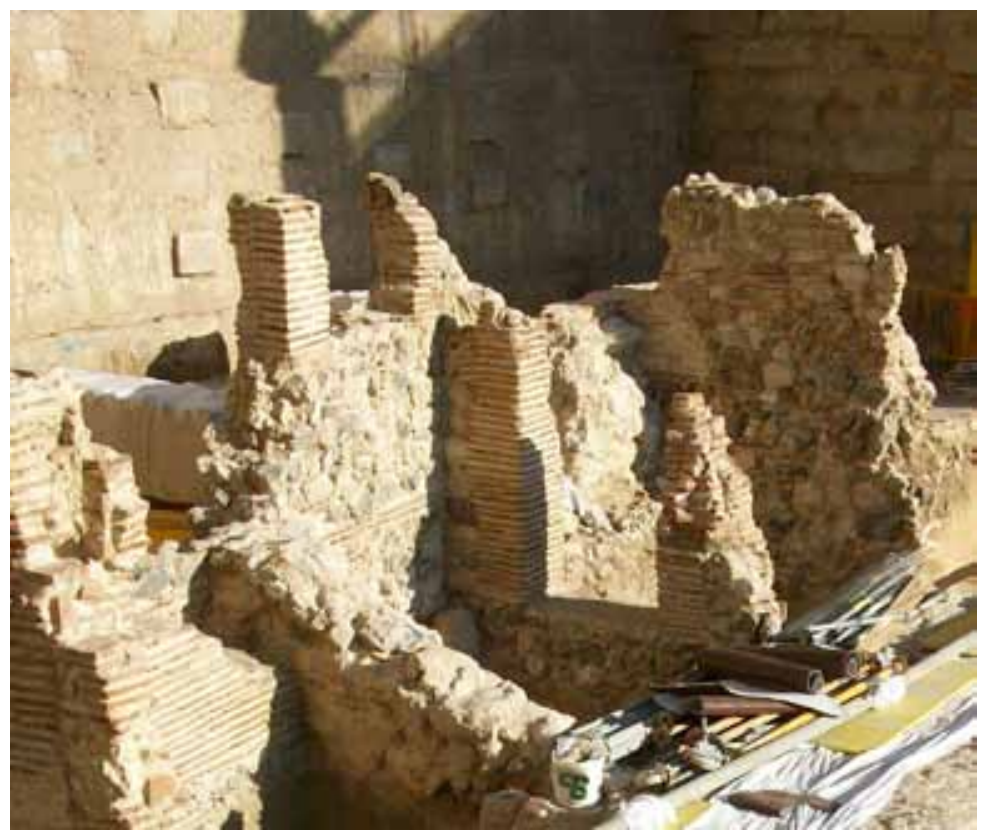

Fig. 5. Restos arquitectónicos de la estructura identificada como posible alojamiento para el cuerpo de guardia (siglo XI. Excavación arqueológica efectuada para la construcción del Museo de las Colecciones Reales).

Este hecho, tiene también bastante sentido si retrocedemos en el tiempo y tratamos de situarnos en los momentos inmediatamente anteriores a la conquista cristiana, cuando los asedios eran habituales y el peligro inminente. La construcción de este espacio, por tanto, ha de ser inserta de nuevo en el marco cronológico del periodo del califato de Córdoba (929-1031), momento histórico del asedio de Ramiro II de León a Mayrit y período clave de la política reformadora de Abd-al-Rahman III.

En cuanto a este edificio, posee un sistema constructivo muy parecido a todas las construcciones califales, tratándose en casi todos los casos de muros realizados con una técnica mixta por lo que han de ser adscritos a los siglos X-XI. Estos muros, tienen la base de mampostería de tipo mediano-grande elevándose una capa de piedras inclinadas sobre la que se asienta otra capa de piedras irregulares horizontales, pero de menor tamaño que en la cimentación. Característico de los muros califales de este primer momento es la presencia abundante de tejas en la mampostería.

Paralelos para esta estructura, tanto de carácter tipológico como cronológico, podemos encontrarlos en el Castelló Soberá de San Miguel de la Vall (Lleida), que disponía de una muralla y, adosado a su parte interior, se documentó una estancia para el cuerpo de guardia fechada en el siglo XI.

Podemos mencionar también el caso de El Castillejo, en los Guájares (Granada), asentamiento defensivo amurallado donde se conservan restos de una estructura rec- 
tangular utilizada como baluarte defensivo y que tendría las funciones de cuerpo de guardia.

Es muy posible que los soldados a los que se destinara dicha guarnición pertenecieran al cuerpo de militares de carrera denominados ahsam, los militares profesionales, lo cual fortalece la idea de la posible existencia de un primitivo ribat de Mayrit. En el ribat de Arrifana (Aljezur, Portugal) se exhumó un conjunto de viviendas con celdas que nos recuerda a nuestra estructura, formada por tres estancias rectangulares de pequeñas dimensiones con diferentes accesos entre ellas y uno principal desde el norte. En relación a su disposición espacial, la exhumación de las estructuras constató que se hallaban dispuestas consecutivamente, siguiendo la alineación de la muralla, y adosándose a ella. Resulta también reseñable, a la hora de identificar esta estructura con un cuerpo de guardia, la cercanía del mismo al portillo de la muralla, ya que es habitual que tanto los cuerpos de guardia como otros elementos defensivos de castillos y fortalezas medievales, se hallasen situados en las inmediaciones de puertas y portillos.

Tan solo en una de las habitaciones se pudieron documentar los restos muy someros, de un pavimento empedrado. Los restos de dicho pavimento bien podrían significar que toda la estructura habitacional del cuerpo de guardia tuviera en sus orígenes un pavimento empedrado en todo el edificio, pero del cual lógicamente, se han conservado apenas unos vestigios. Por otro lado, el hecho de que el pavimento aparezca tan sólo en una de las habitaciones de la estructura podría indicar la posible función de patio de este habitáculo, dado que no es extraño que en ocasiones los patios o espacios al aire libre se pavimenten de algún modo con el fin de evitar las típicas molestias y suciedad provocadas por la mezcla de agua y tierra tras las lluvias.

Por tanto, consideramos plausible que la incipiente población andalusí que convivía junto a las estructuras militares y defensivas, edificara viviendas someras de tapial o jaimas dispersas que no han dejado huella arqueológica, pero cuya existencia podemos suponer gracias a los silos y basureros aparecidos. Su presencia es un claro indicativo de la práctica de actividades ganaderas y agrícolas como medio de abastecimiento de esta inicial guarnición militar.

Asimismo, la aparición de una estructura identificada como un horno y fechada también en época islámica, nos lleva a pensar en la posibilidad de que la función defensiva-castrense contase con un pequeño núcleo de población dedicado a los talleres artesanos y al comercio, complementando así el abastecimiento de los productos de primera necesidad de la guarnición.

\section{CONCLUSIONES}

La pervivencia de estos elementos arquitectónicos de carácter militar podría quizás señalar la existencia inicial de un hisn castral con cierto carácter de ribat. Plaza Fuerte que inicialmente ocuparon gentes de frontera y militares-ascetas que, lógicamente trajeron consigo un reducto de población civil, necesario para asegurar su supervivencia. 
Dada la estratégica situación tanto geográfica como topográfica del enclave elegido, no descartamos esta posible función inicial de ribat donde acudían voluntarios para la guerra santa ${ }^{25}$, de hecho, gracias a las crónicas sabemos que varias campañas contra los reinos cristianos se iniciaron en este punto. Compartimos asimismo, la opinión de ciertos autores que indican que, a partir del siglo X, enclaves como Madrid ${ }^{26}$, Talavera o Tudela acogen murabits que, incorporados a las tropas omeyas, salen en algazúas o razias contra los cristianos y, a la vez, desarrollarán una importante producción mística en los centros fronterizos.

Las actuaciones de restauración y consolidación arqueológica de dichos elementos arquitectónicos, han permitido la conservación in situ de la atalaya, muralla y cuerpo de guardia.

No así del cimiento del albacar, estructura que fue imposible adecuar a las necesidades de la obra del paso subterráneo de la calle de Bailén, tal y como consideró en su día la Dirección General de Patrimonio de la Comunidad de Madrid.

Por el contrario, los restos de la atalaya pueden contemplarse en el aparcamiento subterráneo de la plaza de Oriente. Una vez finalizadas las obras efectuadas con motivo de la construcción de dicho aparcamiento, la atalaya fue integrada en la posterior construcción, tras su restauración y consolidación por parte de un equipo de especialistas. En este sentido, aprovechamos para plasmar nuestras dudas sobre el sentido de conservar restos arqueológicos aislados absolutamente descontextualizados y en cualquier lugar, y abogar por la conservación de un contexto mayor que facilite la comprensión histórica de aquello que se pretende perpetuar en nuestra memoria colectiva. Con respecto a los lienzos de muralla y los restos del cuerpo de guardia exhumados en las excavaciones de la plaza de la Armería, se procederá a su futura musealización toda vez concluyan las obras de construcción del Museo de Colecciones Reales. De este modo, uno de los yacimientos arqueológicos más importantes del núcleo urbano de Madrid se tornará accesible a todo aquel que acuda al museo, acercando el lejano origen islámico de Madrid a la población actual.

25 M. MARÍN, op. cit., 1993; Ibídem, op. cit., 2004.

26 C. MARTÍNEZ SALVADOR, "Arquitectura del ribat en el Sahel tunecino.: modelo y evolución", Anales de prehistoria y arqueología, 13-14 (1997-1998), pp. 251-270; Ibídem, El ribat en el Mediterraneo occidental: lfriqiya y al-Andalus, dos ejemplos de religiosidad (siglos IX-XI d.c.),Madrid, 1995; Ibidem, "Los ribats andalusíes: enclaves militares y centros de transmisión mística", La Rábita en el Islam: estudios interdisciplinares: congressos internacionals de Sant Carles de la Ràpita (1989, 1997), Alicante, 2004, pp. 4958; Ibídem, "Santones guerreros en el Islam Occidental (siglos VIII a XI)", XVII Mediterranean Conference, Murcia, (en prensa). 